\title{
As histórias da história da medicina por Pedro Nava
}

\author{
Rosana Fumie Tokimatsu ${ }^{1}$
}

NAVA, Pedro. Território de Epidauro. Crônicas e histórias da história da medicina. São Paulo: Ateliê Editorial, 2003.

Antes do lançamento de suas Memórias, Pedro Nava era conhecido apenas pela breve participação no movimento modernista em Minas, e por ser desenhista e poeta bissexto, autor do antológico "O defunto". Seus colegas de círculo intelectual apreciavam essas raras incursões, por isso esperavam que ele se firmasse definitivamente como escritor. No entanto, a expectativa nunca se concretizava, em grande parte, talvez, pelo fato de Nava ter se dedicado à profissão de médico em tempo integral. Somente próximo à aposentadoria como reumatologista é que pôde liberar-se inteiramente na literatura. Mas enquanto isso não acontecia, a medicina predominou até em seus escritos. Afora o fato de ter publicado, ao longo da vida, cerca de trezentos artigos e ensaios sobre o assunto em periódicos, também editou trabalhos mais extensos na área: é o caso de seu primeiro livro, Território de Epidauro ${ }^{2}$.

Território reúne, de modo geral, crônicas sobre alguns aspectos da história da medicina, principalmente sobre a história da formação médica no Brasil. Nesse ponto, segue uma linha interpretativa consagrada na época, que produziu obras como Casa-Grande Ct Senzala, de Gilberto Freyre e Raizes do Brasil, de Sérgio Buarque de Holanda, possuindo entretanto maior

1 Mestre em Teoria Literária e Literatura Comparada pela USP.

2 1. ${ }^{a}$ edição: Rio de Janeiro: Cândido Mendes Júnior, 1947. Mais recentemente, foi reeditado também Capitulos da história da medicina no Brasil. (São Paulo: Ateliê Editorial, 2004; 1. a edição: Rio de Janeiro: Brasil Médico Cirúrgico, 1949), que retoma muitos assuntos discutidos no primeiro. Conforme Nava anunciou nos Capitulos, seu plano era lançar continuações desses livros, além de um estudo biográfico sobre o médico João Vicente Torres Homem, compondo assim uma série sobre história da medicina. Contudo, não leva o projeto adiante, tendo deixado inéditos dois extensos ensaios sobre Torres Homem. Cf. AGUIAR, Joaquim Alves de. 0 médico historiador e o memorialista. Novos Estudos CEBRAP, n. 53, p. 151-165, mar. 1999. p. 153. 
afinidade com o primeiro em termos de concepção e estilo. De maneira análoga a estes autores, Nava procura uma identidade, um "caráter brasileiro", porém no campo específico em que atua, e vai mostrando que muito dos rumos da prática médica no Brasil foi determinado pelas vicissitudes de nossa história desde o período colonial.

Contudo, o autor acaba difundindo também idéias polêmicas sobre o nosso processo de formação. Na série de textos sobre as origens francesas da medicina interna brasileira, afirma, cheio de orgulho, que a civilização gaulesa nos legou, entre outras coisas, a concepção do organismo humano como unidade. Assim, não é sem protesto que vê o declínio dessa influência e a ascensão entre nós do cientificismo norte-americano. Para Nava, os manuais de patologia e clínica dos Estados Unidos são muito técnicos e padecem de falta de profundidade, e por isso mesmo, tornam-se apeteciveis para a classe médica (p. 135). Em suma, deve-se afastar tudo o que é capaz de alterar a "orientação tradicional de nossa inteligência", cuja essência seria européia e latina, ou melhor dizendo, francesa (p. 145).

Não se trata aqui de contestar essas observações sobre a contribuição de cada povo ou civilização citados. Entretanto, é curioso o fato de Nava acreditar na existência de uma formação "de base" de nossa tradição médica, que seria principalmente francesa. Desse modo, a influência de outra cultura significaria um retrocesso na ciência brasileira, devendo ser contida pelo fato de macular tal "pureza formativa". Neste ponto nota-se uma analogia com os princípios das teorias eugenistas que atribuíam o atraso do país à mestiçagem e defendiam o controle da entrada de alguns povos nestas terras, muito embora Nava tenha falado somente em cultura e não em raça. Essas idéias tiveram tanta influência sobre ele, que ainda apareceriam nas Memórias do início da década de 70. Em Baú de ossos, ao fazer uma digressão sobre a importância da genealogia, o narrador diz, em suma, que o sangue português deveria predominar sobre os demais, a fim de mantermos certa "unidade" .

No entanto, se por um lado Nava idealiza a civilização do ocidente europeu, por outro detém-se nos componentes não científicos e não civilizados de nossa formação, considerando a importância das práticas populares e das contribuições "genuinamente brasileiras". Para este interesse pelos elementos folclóricos, muito deve ter concorrido o exemplo de Mário de Andrade, de quem aliás tornara-se seguidor no Modernismo dos

3 NAVA, Pedro. Baú de ossos. 3. ed. Rio de Janeiro: José Olympio, Sabiá, 1974. p. 180 . 
anos 1920. Namoros com a Medicina, de Mário, em especial a segunda parte, "A medicina dos excretos", certamente inspirou em Território a reflexão sobre a psicologia profunda dos povos a partir de sua recepção dos remédios e dos tratamentos vulgares. É o caso das crônicas sobre a posição do espírito do doente diante do tratamento, em uma das quais o livro de Mário chega a ser citado.

Além do mais, o trabalho de Nava consiste em uma livre interpretação que não se restringe à objetividade do fato, revelando um princípio transfigurador que recria a história. Como diz o subtítulo do livro, trata-se de uma reunião de histórias da história da medicina, contadas segundo as vivências e as crenças do autor. Suas páginas revestem-se de um caráter literário que não pode ser desconsiderado tão-somente pelos indícios de ideologia que exprimem.

Essa "literariedade" se deve em grande parte ao processo criativo do autor. Ao contar a vida do Dr. Santos Titara, um bem-sucedido médico de subúrbio, Nava descreve o tipo de documentação utilizado para escrever a crônica. 0 material é pouco ortodoxo para a época: fotografias, recortes de jornais, cópias de documentos, receitas e a "conversa de velho", isto é, os depoimentos dos convivas de mestres do passado colhidos por ele. Testemunhos que "repetem as conversas um dia soltas nas varandas, ou em torno às mesas de jantar das casas consumidas" (p. 118).

Ora, o interessante é que o mesmo tipo de arquivo também seria usado na composição das Memórias. Estas só se tornaram possíveis, como Nava disse várias vezes, mediante os documentos pessoais que juntou a vida inteira. Ademais, é decisivo frisar a importância atribuída à "conversa de velho" - a narração oral - como perpetuadora da memória familiar e, por conseguinte, da memória de toda uma comunidade. Nava conheceu primeiramente dentro da própria família a figura desse narrador tradicional, que foi incorporada em grande parte pelo narrador das Memórias ${ }^{4}$.

Segundo o autor, em Território, os depoimentos focalizam "pequenos detalhes e os fragmentos de humanidade" importantes, mas que não figuram nos chamados "documentos declarados” (p. 117). Tal comentário vale também para os demais tipos de documentos do seu arquivo, que podem igualmente re-

4 Sobre as marcas em Território de Epidauro e Capitulos da história da medicina que antecipam o escritor das Memórias, v. também AGUIAR, Joaquim Alves de. 0 médico historiador e o memorialista. Novos Estudos CEBRAP, n. 53, p. 151-165, mar. 1999. 
velar facetas originais sobre qualquer assunto, ajudando assim a contar uma "história não-oficial" de nossa medicina. Diga-se de passagem que o livro teve origem, em grande parte, na pesquisa dessas fontes então "marginais", ou de importância despercebida. A sensibilidade para valorizar o que é aparentemente irrelevante faz com que o autor transforme em assunto de crônica, por exemplo, uns manuscritos do século XVIII que encontrou por acaso dentro de um volume de medicina portuguesa, e que lhe permitiram ressaltar a incorporação, já naquela época, de ervas da flora nativa na medicina popular.

Ainda no texto sobre o Dr. Titara, Nava continua a falar sobre o próprio modo de compor. As informações que colheu a respeito desse médico são, segundo diz, parcas e longínquas; no entanto, afirma, em contrapartida: "é por serem assim que permitem evocar a figura do prático, na meia-luz propícia à interpretação poética de sua vida" (p. 119). 0 trabalho criativo não provém de pura reconstituição documental, pois as lacunas que a pesquisa não pôde preencher são supridas pela imaginação naveana, que concede “interpretação poética” ao fato. É justamente neste ponto que reside o caráter literário do livro. Por sua vez, o misto de realidade e ficção é uma das principais características das Memórias. Nesta obra, para ilustrar processo semelhante ao que relata em Território, o autor compara-se a Cuvier que, partindo apenas de um dente, reconstruiu aos poucos todo o esqueleto da besta ${ }^{5}$. Através da reminiscência e da poesia, Nava sempre possuiu o dom de converter as ruínas do tempo em um mundo palpitante de vida.

Para se ter uma idéia desse processo, cito um trecho de crônica sobre a contribuição dos feiticeiros e curadores à medicina clássica. No período que o autor localiza entre a morte de Galeno e a Renascença, o pensamento humano, e com efeito, a medicina, sofrem estagnação devido, entre outras causas, a vários episódios de repressão e conquistas, como as invasões bárbaras e a Inquisição. Dessa forma, o feiticeiro tornou-se o grande médico do povo:

É dentro dessa noite escura que se movem os feiticeiros. Guiados pela força invencível da tendência - lucíferes isolados desafiando as fustigações, as cunhas, as fogueiras e as estrapadas - bruxos e sagas procuram nos ermos e nas humildades sua farmácia maldita. [...] Flores lívidas e viscosas do estramônio. E a solanácea das solanáceas - a apaziguadora beladona. Eram

5 NAVA, Pedro. Baú de ossos. 3. ed. Rio de Janeiro: José Olympio, Sabiá, 1974. p. 41. 
as plantas do bem-estar, as ervas consoladoras que o povo ia buscar com os prepostos do Demônio. [...] (p. 110).

Note-se que o ponto de partida é uma informação histórica, mas genérica: a manipulação de ervas pela feitiçaria. No entanto, o autor se encarrega de ficcionalizar, criando uma situação na qual os feiticeiros são retratados de acordo com o imaginário que comumente lhes é associado: são assustadores, demoníacos, e como tais, desafiam o cerco proibitivo ao agir na "noite escura", procurando nos "ermos" e nas "humildades" a matéria-prima para as suas poções.

Enfim, com Território de Epidauro, Pedro Nava mostrou que, aparentemente se afastando da literatura, estava mais próximo dela do que talvez pudesse imaginar. Ao se entregar de corpo e alma à medicina, dedicando-lhe até mesmo o seu primeiro livro, já acabou, por via diversa, revelando o método, a visão humanística e a força da reminiscência e da poesia que fariam dele um escritor de memórias. 